\title{
Childhood adversity, mental health, and the perpetration of physical violence in the adult intimate relationships of women prisoners: A life course approach
}

Melissa S. Jones

Brigham Young University - Provo, melissa.s.jones@byu.edu

Stephanie W. Burge

University of Oklahoma

Susan F. Sharp

University of Oklahoma

Eollow this and additional works at: https://scholarsarchive.byu.edu/facpub

ivenstityf $Q$ KOBlahraralc and Intimate Partner Violence Commons, Family, Life Course, and Society

Commons, Gender and Sexuality Commons, Social Control, Law, Crime, and Deviance Commons, and the Social Psychology and Interaction Commons

\section{Original Publication Citation}

Jones, Melissa S., Stephanie W. Burge, Susan F. Sharp, and David. A. McLeod. 2020. "Childhood Adversity, Mental Health, and the Perpetration of Physical Violence in the Adult Intimate Relationships of Women Prisoners: A Life Course Approach." Child Abuse \& Neglect.

\section{BYU ScholarsArchive Citation}

Jones, Melissa S.; Burge, Stephanie W.; Sharp, Susan F.; and McLeod, David A., "Childhood adversity, mental health, and the perpetration of physical violence in the adult intimate relationships of women prisoners: A life course approach" (2020). Faculty Publications. 4092.

https://scholarsarchive.byu.edu/facpub/4092

This Peer-Reviewed Article is brought to you for free and open access by BYU ScholarsArchive. It has been accepted for inclusion in Faculty Publications by an authorized administrator of BYU ScholarsArchive. For more information, please contact ellen_amatangelo@byu.edu. 
Research article

\title{
Childhood adversity, mental health, and the perpetration of physical violence in the adult intimate relationships of women prisoners: A life course approach
}

\author{
Melissa S. Jones $^{\mathrm{a}, *}$, Stephanie W. Burge ${ }^{\mathrm{b}}$, Susan F. Sharp ${ }^{\mathrm{b}}$, David A. McLeod ${ }^{\mathrm{b}}$ \\ ${ }^{\text {a } B r i g h a m ~ Y o u n g ~ U n i v e r s i t y, ~ U n i t e d ~ S t a t e s ~}$ \\ ${ }^{\mathrm{b}}$ University of Oklahoma, United States
}

\section{A R T I C L E I N F O}

\section{Keywords:}

Adverse childhood experiences

Mental health

Perpetration of physical violence

Life course perspective

Incarcerated women

\begin{abstract}
A B S T R A C T
Background: Adverse childhood experiences (ACEs) are common, with nearly two-thirds of adult samples reporting exposure to at least one and one-quarter reporting exposure to three or more distinct types of ACEs. ACEs have been linked to various negative outcomes across the life course, including mental health problems, and the perpetration of physical violence in intimate relationships. However, little is known about the relationships between ACEs, PTSD symptomology, and use of physical violence against an adult intimate partner among incarcerated women.

Objective: The purpose of this paper is to examine the relationships between ACEs, PTSD symptoms, and the perpetration of the physical violence in the adult intimate relationships of women prisoners.

Methods: Using data from the 2014 Oklahoma Study of Incarcerated Mothers and Their Children $(N=349)$ and structural equation modeling (SEM) techniques, we investigate the potential mediating effect of PTSD symptoms in the relationship between ACEs and perpetrating violence against an intimate partner.

Results: Our findings indicate that PTSD symptomology fully mediates the relationship between ACEs and the perpetration of physical violence against an adult intimate partner, indicating that PTSD experiences may be central to understanding women's pathways toward violence.

Conclusions: Women prisoners who were exposed to ACEs during childhood were at a particularly elevated risk of developing PTSD symptomology and perpetrating physical violence against an adult intimate partner. Based on the current study's findings, treatment programs that address these complex relationships between ACEs, particularly focusing on the central role of mental health in these processes, are needed for incarcerated women.
\end{abstract}

\section{Introduction}

A growing body of research has examined the effects of adverse childhood experiences (ACEs) on life outcomes across the life course. These research efforts have concluded that children who are exposed to ACEs during childhood are at an increased risk for various negative outcomes in adolescence and adulthood, such as mental health problems, including posttraumatic stress disorder (PTSD) (Brown, Perera, Masho, Mezuk, \& Cohen, 2015; Hellmuth, Jaquier, Young-Wolff, \& Sullivan, 2013; Kendra, Bell, \& Guimond,

\footnotetext{
* Corresponding author.

E-mail address: melissa.s.jones@byu.edu (M.S. Jones).
} 
2012), as well as perpetrating violence against an adult intimate partner (Mckinney, Caetano, Ramisetty-Mikler, \& Nelson, 2009; Milaniak \& Widom, 2015; Miller et al., 2011; Paat \& Markham, 2019). ACEs are common in the general population, with nearly twothirds of adult samples reporting exposure to at least one and one-quarter reporting exposure to three or more distinct types of ACEs (Merrick, Ford, Ports, \& Guinn, 2018). Moreover, adverse childhood events are especially prevalent in the lives of women who are involved with the criminal justice system. Most incarcerated women report extensive histories of ACEs, including abuse, neglect, and/ or growing up in a chaotic or dysfunctional home environment, mental health problems, and involvement in various criminogenic behaviors (e.g., substance abuse) (DeHart, Lynch, Belknap, Dass-Brailsford, \& Green, 2014; Grella, Stein, \& Greenwell, 2005; Jones, Worthen, Sharp, \& McLeod, 2018; Sharp, Peck, \& Harstfield, 2012). Indeed, studies consistently report that in comparison to nonincarcerated women, incarcerated women have significantly higher rates of ACEs and mental illnesses overall (Grella, Lovinger, \& Warda, 2013; Wolf et al., 2011). Specifically, 70-90\% of incarcerated women report experiences with ACEs (Bowles, DeHart, \& Webb, 2012; Messina, Grella, Burdon, \& Prendergast, 2007; Owen, 1998; Sharp, 2014) and over two-thirds report suffering from a mental illness (Bronson \& Berzofsky, 2017) often in response to these traumatic and abusive early life experiences.

While it is clear that women prisoners experience ACEs, which may be linked to their mental health problems and subsequent criminogenic behaviors, we know considerably less about incarcerated women's pathways to perpetrating physical violence against an adult intimate partner, including how PTSD symptoms may mediate the relationship between ACEs and use of physical violence. Drawing upon both the life course perspective as well as insights from research on ACEs, the current study addresses this gap in the literature by investigating how ACEs may be associated with the perpetration of physical violence in the intimate relationships of women prisoners. Given the documented association between ACEs and psychological distress (Jones, Nurius, Song, \& Fleming, 2018; Lowe et al., 2016; Merrick et al., 2017; Taillieu, Brownridge, Sareen, \& Afifi, 2016), we examine PTSD symptoms as a potential mediating variable in the relationship between ACEs and violence perpetration. The findings from this study not only provide insights into the complexities surrounding the relationships between trauma, mental illness, and offending behaviors, but also may inform current treatment needs of incarcerated women. The follow research questions guide this study:

RQ1: How do ACEs influence PTSD symptoms and the perpetration of physical violence in the adult intimate relationships of women prisoners?

RQ2: Do PTSD symptoms mediate the relationship between ACEs and the perpetration of physical violence in the adult intimate relationships of women prisoners?

\section{The life course perspective and adverse childhood experiences (ACEs)}

The life course perspective emphasizes a developmental approach for understanding heterogeneity in individuals' experiences and outcomes in adulthood, asserting that early life course events and transitions have longer-term impact and shape the trajectories of human lives with respect to educational attainment, health outcomes, and family formation behaviors (Dannefer, 2011; Elder, Johnson, \& Crosnoe, 2003; Montez \& Hayward, 2014; Schafer, Wilkinson, \& Ferraro, 2013; Umberson, Williams, Thomas, Liu, \& Thomeer, 2014). In addition, the life course perspective highlights the ways that lives are linked together interdependently, with the understanding that individuals' decisions and behaviors both affect and are influenced by others in their lives (Elder, 1994; Settersten, 2015). As such, this perspective draws our attention to the role of families in shaping early exposure to ACEs, as well as the ways in which the early timing and clustering of these adverse childhood events are likely to accumulate to further disadvantage in adulthood (Felitti et al., 1998).

A well-established body of life course literature has demonstrated that early life events which confer disadvantage, such as those detailed in the Adverse Childhood Experiences (ACE) Study (Felitti et al., 1998), are negatively associated with outcomes in the transition to adulthood, as well as in later life (Merrick et al., 2017; Nurius, Green, Grenne-Logan, \& Borja, 2015). These adverse events include experiences such as sexual, physical, and emotional abuse, physical and emotional neglect, having witnessed violence at home, having lived with someone with a mental illness, parental separation or divorce, parental incarceration, and household alcohol or illicit drug problems. Researchers utilizing the ACE study have found that ACEs increase the risk of early and chronic drug dependency (Dube et al., 2003; Mersky, Topitzes, \& Reynolds, 2013), histories of attempted suicide (Dube et al., 2001; Merrick et al., 2017), and involvement in abusive intimate relationships (Ports, Ford, \& Merrick, 2016; Whitfield, Anda, Dube, \& Felitti, 2003). Other studies have also found that ACEs interfere with human capital acquisition (Covey, Menard, \& Franzese, 2013; Currie \& Widom, 2010; Elman \& O'Rand, 2004; Wagmiller, Lennon, Kuang, Alberti, \& Aber, 2006), which in turn places those who experience early adversity at greater risk for poorer health outcomes in adulthood (Schafer, Ferraro, \& Mustillo, 2011). It is also important to note the interrelatedness of ACEs. There is a tendency for ACEs to cluster, such that exposure to one type of abuse, neglect, or chaotic home environment ACE is likely to be significantly associated with exposure to additional ACEs (Dong et al., 2004).

In addition, early exposure to childhood trauma, abuse, and violence is associated with greater psychological distress and other mental health problems in adulthood, including post-traumatic stress and depression symptoms (Chapman et al., 2004; Jones, Nurius et al., 2018; Lowe et al., 2016; Taillieu et al., 2016; Widom, 1999), personality disorders, (Afifi et al., 2011), and behavioral problems (McLaughlin et al., 2012), in part because childhood exposure to adverse events tends to accumulate over the early life course (MillerGraff, Scrafford, \& Rice, 2016). In particular, previous research suggests that there is a strong dose-response for the relationship between ACEs and mental health in that exposure to multiple ACEs is associated with increased risk of depression and PTSD symptoms (Chapman et al., 2004; Merrick et al., 2017). 


\section{ACEs, PTSD, and perpetration of physical violence in the adult intimate relationships}

Most research that has examined women's use of physical violence in intimate relationships has focused on women using violence in response to violence initiated against them by an abusive male partner (for reviews see Bair-Merritt et al., 2010; Hamberger \& Larsen, 2015). However, ACEs are often overlooked in such explorations, particularly in studies that examine women who are incarcerated. Overall, there is significant evidence to suggest that ACEs increase the risk for perpetration of physical violence against an adult intimate partner for non-incarcerated women (Mckinney et al., 2009; Milaniak \& Widom, 2015; Miller et al., 2011; Widom, Czaja, \& Dutton, 2014). More specifically, women who witnessed violence between parents or experienced child maltreatment were significantly more likely to report using physical violence against an intimate partner compared to women who did not witness or experience violence (Milaniak \& Widom, 2015; Paat \& Markham, 2019; Roberts, McLaughlin, Conron, \& Koenen, 2011; Temple, Shorey, Tortolero, Wolfe, \& Stuart, 2013). Other studies indicate that women who are exposed to a high number of ACEs are at an increased risk of using violence in their adult intimate relationships than women with fewer ACEs (Miller et al., 2011; Roberts et al., 2011).

The association between ACEs and use of physical violence against an intimate partner may also be mediated by psychosocial factors (Brown et al., 2015; Hellmuth et al., 2013; Kendra et al., 2012). Indeed, there is strong evidence to suggest that exposure to abuse and trauma in childhood is associated with greater levels of PTSD symptoms and use of violence coping (Brown et al., 2015; Hellmuth et al., 2013; Sullivan, Meese, Swan, Mazure, \& Snow, 2005; Swan, Gambone, Fields, Sullivan, \& Snow, 2005). PTSD is a serious and potentially debilitating condition that can occur as a response to experiencing or witnessing traumatic or terrifying events in which serious harm occurred or was threatened (Jones, Peck, Sharp, \& McLeod, 2019). Symptoms of PTSD can include flashbacks, nightmares, severe anxiety, avoidance coping, uncontrollable thoughts about the event(s) and even anger (Golding, 1990; Weathers, Litz, Herman, Huska, \& Keane, 1993). Moreover, PTSD symptoms can be long lasting and multiple studies have shown that current levels of PTSD are often directly linked to ACEs (Chapman, Dube, \& Anda, 2007; Dye, 2018; Greenfield \& Marks, 2010; Merrick et al., 2017) and perpetrating violence against an adult intimate partner (Brown et al., 2015; Hellmuth et al., 2013; Kendra et al., 2012; Sullivan et al., 2005). Thus, is it important to continue to investigate the relationships between ACEs, PTSD symptoms, and violence perpetration, particularly among incarcerated women, a population that demonstrates consistently high exposure to ACEs.

\section{ACEs, PTSD, and perpetration of physical violence in the adult intimate relationships of women prisoners}

Research focusing on ACEs among women prisoners finds that incarcerated women are significantly more likely than incarcerated men (Belknap \& Holsinger, 2006; McClellan, Farabee, \& Crouch, 1997; Messina et al., 2007; Roxburgh \& MacArthur, 2014) and women in the general population to report lifetime trauma and abuse (Bloom, Owen, \& Covington, 2003; Grella et al., 2013; Sharp, 2014). Moreover, women prisoners report significantly higher number of ACEs than women in the general population with incarcerated women reporting 5 or more ACEs compared to approximately 2 or fewer ACEs in comparison samples (Grella et al., 2013; Messina \& Grella, 2006; Sharp, 2014). Even more alarming, some recent studies indicate that some women prisoners report as many as 8 or more ACEs (Jones, Worthen, Sharp, \& McLeod, 2018; Sharp, 2014). The high exposure to ACEs in the lives of women prisoners has been strongly connected to their development of mental illnesses as well as offending behaviors. Indeed, PTSD symptomology is 4-10 times more prevalent among incarcerated women than non-incarcerated women (Wolf et al., 2011). Furthermore, women prisoners' who report ACEs and mental illnesses also report substance abusing behaviors which are often used to cope with their psychological distress in response to experienced ACEs (Bowles et al., 2012; DeHart et al., 2014; Grella et al., 2005; Jones, Worthen, Worthen et al., 2018; Messina et al., 2007; Sharp et al., 2012).

Though previous studies have well-documented relationships between ACEs, mental health, and violence perpetration for women in the non-incarcerated population, we know considerably less about the role of ACEs and PTSD symptomology in women's use of physical violence in adult intimate relationships among women prisoners, as these studies have been scarce. One recent study found that the relationship between ACEs and violence perpetration (against an intimate partner and/or a non-partner) was mediated by mental illness (Kubiak, Fedock, \& Kim, 2017). While there is some evidence to suggest that PTSD symptomology may mediate the relationship between ACEs and the perpetration of physical violence against an intimate partner, a better understanding of the relationships between ACEs, PTSD symptoms, and violence perpetration in the adult intimate relationships of women prisoners is clearly warranted.

\subsection{The current study}

Using a life course theoretical framework, the current study examined the links between ACEs, PTSD symptoms, and perpetration of physical violence against an adult intimate partner using data from a sample of incarcerated women in Oklahoma $(N=349)$. This study moves beyond previous explorations of ACEs in the lives of women prisoners by specifically focusing on pathways to perpetrating violence in adult intimate relationships, including the potential mediating role of PTSD symptomology in the relationship between ACEs and the use of physical violence. This investigation endeavors to further understand the complex relationships between trauma, mental health, and offending behaviors for justice involved women. Moreover, findings from this study may inform approaches in treatment and care for incarcerated women. Specifically, the following hypotheses are investigated:

Hypothesis 1. ACEs will be positively associated with both the use of physical violence

against an adult intimate partner and PTSD symptomology. 
Hypothesis 2. PTSD symptoms will mediate the relationship between ACEs and the use of physical violence against an adult intimate partner.

\section{Data and methods}

\subsection{Sample}

The data for this study are drawn from the 2014 Oklahoma Study of Incarcerated Mothers and Their Children. Participants were sampled from the only three women's correctional facilities in the state of Oklahoma at that time: Mabel Bassett Correctional Center (MBCC), Dr. Eddie Warrior Correctional Center (EWCC), and Kate Bernard Community Correctional Center (KBCCC). The researchers were not provided access to the full population nor demographics about the full population. Instead, the Oklahoma Department of Corrections provided the researchers with a random sample of 500 women prisoners that were stratified by age, race, and security level. Controlling for demographics of the study sample $(\mathrm{N}=500)$, the researchers assigned each woman with a randomly generated identification number, the list was sorted by identification numbers, and the first 1 to $\mathrm{N}$ women were selected from each list for each facility. Comparisons of the study sample with the full population demographics conducted by the Oklahoma Department of Corrections confirmed that the study sample did not differ statistically from the Oklahoma's women prisoner population on any of the selected demographics, such as age, race or security level. To minimize sample attrition due to discharges, transfers, or segregation, all three samples were drawn the business day before the survey was undertaken; however, some women were unavailable due to work assignments, transfer, or being placed in segregated housing. Participants were given a 26-page self-administered paper/pencil questionnaire containing questions about their criminal record, abuse histories, family lives and other demographic characteristics. Inmates were instructed ${ }^{1}$ that completion of the questionnaire was voluntary and no compensation was provided. Out of 500 women, 367 completed questionnaires for an overall response rate of 73.4 percent. After excluding records with missing data on key variables in our study, the final analysis sample consisted of 349 women.

\subsection{Perpetration of physical violence}

The latent dependent variable of physical violence is represented by two indicators: (1) simple assault, and (2) aggravated assault. ${ }^{2}$ Simple assault and aggravated assault indices were created using measures from The Revised Conflict Tactics Scale (CTS2) (Straus, Hamby, Boney-McCoy, \& Sugarman, 1996). Simple assault was measured by asking the participant whether she had done any of the following six acts to her intimate partner in the last 12 months of her most recent relationship before coming to prison: (1) "I grabbed my partner," (2) "I pushed or shoved my partner," (3) "I threw something at my partner that could hurt," (4) "I slapped my partner," (5) "I twisted my partner's arm or hair," and (6) "I kicked my partner." Affirmative responses to each of the six acts were summed together into an index representing simple assault (Cronbach's alpha $=.84$ ). Aggravated assault was measured by asking the participant whether she had done any of the following six acts to her intimate partner in the last 12 months of her most recent relationship before coming to prison: (1) "I punched or hit my partner with something that could hurt," (2) "I slammed my partner against a wall," (3) "I choked or strangled my partner," (4) "I burned or scalded my partner on purpose," (5) "I beat my partner up," and (6) "I used or threatened to use a knife or gun." Affirmative responses to each of the six acts were summed together into an index representing aggravated assault (Cronbach's alpha $=.80$ ).

\subsection{Adverse childhood experiences (ACEs)}

The latent independent variable adverse childhood experiences (ACEs) is represented by 10 indicators: physical neglect, emotional neglect, emotional abuse, physical abuse, sexual abuse, having an immediate family member who went to prison, battered mother, parental separation or divorce, lived with someone with a mental illness, and lived with someone with a substance abuse problem. Respondents were asked about their adverse and abusive experiences during their first 18 years of life. Childhood physical neglect was coded 1 if the respondent reported that she did not feel protected as a child, did not have enough to eat, often had to wear dirty clothes, or had nobody to take her to the doctor when she was sick. Those that did not indicate any of these experiences were coded 0. Childhood emotional neglect was coded 1 if the respondent reported that she did not feel loved as a child, that there was nobody who made her feel important, that nobody looked out for her well-being, or that she thought her parents wished she was never born. Those that did not indicate any of these experiences were coded 0. Childhood emotional abuse was coded 1 if the respondent reported that she was called names as a child. Childhood physical abuse was coded 1 if the respondent reported "yes" to ever being physically abused as a child, and childhood sexual abuse was coded 1 if the respondent reported "yes" to ever being sexually abused as a child. Those indicating "no" were coded 0 . Family member incarcerated was coded 1 if a participant reported that a member of their household was incarcerated during the first 18 years of her life. Battered mother was coded 1 if the participant reported that her father had ever been violent to her mother or stepmother during the first 18 years of her life. Parental separation or

\footnotetext{
${ }^{1}$ Three of the authors were present during the administration of the survey to answer any clarification questions asked by participants.

${ }^{2}$ Only $13(3.7 \%)$ of the women reported using sexual assault against their intimate partner prior to incarceration. We did explore the effects of ACEs and PTSD symptoms on use of with sexual assault as an indicator of violence; however, the factor loading for sexual assault was below .5 (b = .06) and was not statistically significant. Thus, we did not include sexual assault as an indicator of use of violence in the final models.
} 
divorce was coded 1 if participants reported their parents had ever been separated or divorced during the first 18 years of her life. Affirmative answers to questions asking whether the respondent had lived with someone with a mental illness or lived with someone with substance use during the first 18 years of her life were each coded as 1 . All others were coded 0.

\subsection{Posttraumatic stress disorder (PTSD)}

The latent mediating variable posttraumatic stress disorder (PTSD) was measured using three indicators: re-experiencing, avoidance and numbing, and arousal symptoms, which was measured using the PTSD Checklist-Civilian Version (PCL) (Weathers et al., 1993). This measure required participants to indicate on a 5-point scale the degree of distress they experienced for each of the seventeen PTSD symptoms indicated in DSM-IV. ${ }^{3}$ Re-experiencing was measured by asking participants if they were bothered by the following four experiences: repeated disturbing memories, repeated disturbing dreams, suddenly feeling as though the abuse were happening again, and feeling very upset when something reminded them of their past abuse. Response categories ranged from (1) "not at all" to (5) "extremely." Each PTSD symptom was recoded into a dummy variable with "extremely," "quite a bit," and "moderately" coded as 1 representing symptomatic, while "not at all" and "a little bit" were coded as 0 (non-symptomatic). We then summed the four re-experiencing symptoms into an index (0-4), with a Cronbach's alpha of .86.

Avoidance and numbing was measured by asking participants if they were bothered by the following six experiences: avoided thinking about it or talking about abuse, avoided situations that reminded the participant of the abuse, had trouble remembering important parts of the abuse, felt a loss of interest in activities that she used to enjoy, feeling emotionally numb, and feeling distant or cut off from other people. Response categories ranged from (1) "not at all" to (5) "extremely." Each PTSD symptom was recoded into a dummy variable with "extremely," "quite a bit," and "moderately" coded as 1 representing symptomatic, while "not at all" and "a little bit" were coded as 0 (non-symptomatic). We then summed the six avoidance and numbing symptoms into an index (0-6), with a Cronbach's alpha of .88. Arousal symptoms was measured by asking participants if they were bothered following seven experiences: feeling as though her future was somehow to be cut short, had trouble falling asleep or staying asleep, feeling irritable or having angry outbursts, having difficulty concentrating, being "super-alert" or watchful or on guard, feeling jumpy or easily started, and having physical reactions when something reminded her of a stressful experience. Response categories ranged from (1) "not at all" to (5) "extremely." Each PTSD symptom was recoded into a dummy variable with "extremely," "quite a bit," and "moderately" coded as 1 representing symptomatic, while "not at all" and "a little bit" were coded as 0 (non-symptomatic). We then summed the seven arousal symptoms into an index (0-7), with a Cronbach's alpha of .91.

\subsection{Control variables}

Demographic characteristics were utilized as controls. Age was measured by respondents' self-identified age in years and ranged from 18 to 69. Race/ethnicity was measured through self-identification. The possible responses categories were White, African American, Native American, Hispanic, and Other. In the analyses, this variable was recoded into dummy variables representing African American, Native American, Hispanic/Other, ${ }^{4}$ with White as the reference group.

Education was measured by asking participants to report their level of education prior to prison. The possible response categories were " $8^{\text {th }}$ grade or less," " $9^{\text {th }}-11^{\text {th }}$ grade," "high school graduate or GED," "Vo-tech school," "up to 2 years of college (no degree) or associates degree (2 years)," "more than 2 years of college but no degree," "4 years of college (degree)," and "post-graduate school." In the analyses, we recoded education into dummy variables representing education as high school $(E d u c=H S)$, education greater than high school $(E d u c>H S$ ), with less than high school representing the reference category. Marital status was measured by asking participants their marital status at the time they were arrested for the offense for which they were currently serving time. The possible responses were "married," "not married but living with a male partner," "not married but living with a female partner," "divorced," "separated," "widowed, no partner," and "widowed living with partner." In the analyses, marital status was recoded into dummy variables representing cohabit (affirmative responses to not married but living with a male partner, not married but living with a female partner, and widowed but living with a partner), not married/widowed (affirmatives responses to divorced, separated, and widowed no/partner), with married representing the reference group.

\subsection{Statistical analyses}

Structural equation modeling (SEM) was used to explore the relationships between ACEs, PTSD, and use of violence. SEM offers several advantages over other analytic methods. First, as demonstrated in the present analyses, it allows for the estimation of multiple equations simultaneously, so that the association between multiple predictor and outcome variables can be assessed in the same model. SEM specifies hypothesized relationships between observed variables and their latent constructs and the relationships among latent constructs in the model. The measurement model describes the hypothesized relationship between a number of measurement variables and the latent or unobserved constructs. The structural relations model expresses the hypothesized causal relationships

\footnotetext{
${ }^{3}$ There have been some changes in the PTSD diagnostic criteria from the DSM-IV to the DSM- 5 . The DSM- 5 pays more attention to the behavioral symptoms that accompany PTSD and proposes four distinct diagnostic clusters instead of three: re-experiencing, avoidance, negative cognitions and moods (new addition), and arousal (American Psychiatric Association, 2013).

${ }^{4}$ Due to the small number of Hispanic respondents, these participants were combined with those who identified as "Other."
} 
Table 1

Sample Characteristics $(\mathrm{N}=349)$.

\begin{tabular}{|c|c|c|c|}
\hline & Range & Frequency & Percent \\
\hline \multicolumn{4}{|l|}{ Individual ACEs } \\
\hline Childhood Physical Neglect & $0-1$ & 189 & 54.2 \\
\hline Childhood Emotional Neglect & $0-1$ & 220 & 63.0 \\
\hline Childhood Emotional Abuse & $0-1$ & 159 & 45.6 \\
\hline Childhood Physical Abuse & $0-1$ & 169 & 48.4 \\
\hline Childhood Sexual Abuse & $0-1$ & 203 & 58.2 \\
\hline Family Member Incarcerated & $0-1$ & 117 & 33.5 \\
\hline Battered Mother & $0-1$ & 129 & 37.0 \\
\hline Parental Separation or Divorce & $0-1$ & 241 & 69.1 \\
\hline Lived w/Someone with Mental Illness & $0-1$ & 162 & 46.4 \\
\hline Lived w/Someone with Substance Use & $0-1$ & 261 & 74.8 \\
\hline \multicolumn{4}{|l|}{ PTSD Symptoms } \\
\hline$\overline{\text { Re-experiencing, }}$ (mean $=1.9$ ) & $0-4$ & 246 & 70.5 \\
\hline Avoidance and Numbing, $($ mean $=3.1)$ & $0-6$ & 265 & 75.9 \\
\hline Arousal Symptoms, $($ mean $=3.6)$ & $0-7$ & 282 & 81.0 \\
\hline \multicolumn{4}{|l|}{ Physical Violence } \\
\hline Simple Assault, $($ mean $=1.5)$ & $0-6$ & 189 & 54.2 \\
\hline Aggravated Assault, $($ mean $=0.7)$ & $0-6$ & 103 & 29.5 \\
\hline \multicolumn{4}{|l|}{ Demographics } \\
\hline Age, mean & $20-65$ & & 36.0 \\
\hline \multicolumn{4}{|l|}{ Race } \\
\hline White (reference category) & $0-1$ & 177 & 49.3 \\
\hline African American & $0-1$ & 52 & 14.9 \\
\hline Native American & $0-1$ & 51 & 14.6 \\
\hline Other/Hispanic & $0-1$ & 74 & 21.2 \\
\hline \multicolumn{4}{|l|}{ Education at Incarceration } \\
\hline Education < High School (reference category) & $0-1$ & 138 & 39.5 \\
\hline Education $=$ High School & $0-1$ & 120 & 34.4 \\
\hline Education $>$ High School & $0-1$ & 91 & 26.5 \\
\hline \multicolumn{4}{|l|}{ Marital Status } \\
\hline Married (reference category) & $0-1$ & 83 & 23.8 \\
\hline Cohabit & $0-1$ & 114 & 32.7 \\
\hline Not Married/Widowed & $0-1$ & 152 & 43.5 \\
\hline \multicolumn{4}{|l|}{ Incarcerated Offense } \\
\hline Alcohol- or Drug- Related Offenses & & 141 & 41.0 \\
\hline Crimes Against People & & 135 & 38.7 \\
\hline Property Related Crimes & & 73 & 20.3 \\
\hline
\end{tabular}

among latent constructs as regression coefficients. This procedure also evaluates the estimated models and obtains maximum-likelihood estimates of model parameters, and goodness-of fit indices. A model that provides a good fit to the data is generally considered one that has a root mean square of approximation (RMSEA) value of less than .05 with a p test for closeness of fit for RMSEA of .05 (Browne \& Cudeck, 1992) and a comparative fit index (CFI) with a value close to 1 (Bentler, 1990).

The analyses were conducted in two stages. First, the Baseline Model was estimated specifying the effects of ACEs on the perpetration of physical violence against an intimate partner. Using that model as a basis for comparison, the second model was estimated decomposing the effects of ACEs on the perpetration of physical violence by specifying PTSD symptoms as the mediating variable (the Theoretical Model). ACEs are modeled as influencing PTSD symptoms and physical violence perpetrated against an intimate partner. The PTSD symptoms variable is modeled as influencing the perpetration of physical violence. Social demographic characteristics are modeled as influencing ACEs, PTSD symptoms, and physical violence against an intimate male partner.

\section{Results}

\subsection{Sample characteristics of Oklahoma women prisoners}

Table 1 presents the basic descriptive statistics for the key observed variables in the analyses. The average age of the sample of women prisoners was 36. There were 177 Whites (49.3 percent), 52 African Americans (14.9 percent), 51 Native Americans (14.6 percent), and 74 Other/Hispanics (21.2 percent). Education levels were low, with 138 (39.5 percent) women having less than high school education, 120 (34.4 percent) reporting high school graduation or GED, and the remaining 91 (26.5 percent) reporting 
education beyond high school including vocational and college. Marriage was not common in the sample, with 83 (23.8 percent) women reporting being married, 114 women reporting cohabitation (32.7 percent), and 152 (43.5 percent) women reporting they were not married, separated, divorced, or widowed prior to incarceration. The most common offense types for which these women were currently incarcerated ${ }^{5}$ included crimes against people (41.0 percent) alcohol-and-drug-related offenses (38.7 percent), and property related crimes (20.3 percent), which closely matches the incarcerated offenses of the women's prison population in Oklahoma (ODOC, 2015).

The individual ACEs show that the majority of women prisoners in Oklahoma have experienced various forms of adverse events in childhood. The most commonly experienced adverse events in childhood were having lived with someone with a substance abuse problem (74.8 percent), parental separation or divorce (69.1 percent), emotional neglect (63.0 percent), sexual abuse (58.2 percent), and physical neglect (54.2 percent). PTSD symptomology was quite high in the sample with 70.5 percent of the women reported having re-experiencing PTSD symptoms, 75.9 percent reported avoidance and numbing PTSD symptoms, and 81.0 percent reported PTSD arousal symptoms. More than half of the women (54.2 percent) in the sample reported using simple assault against their most recent intimate partner prior to incarceration. Moreover, approximately one-third (29.5 percent) reported using aggravated assault against their most recent intimate partner before coming to prison.

\subsection{Baseline model}

The standardized factor loadings of the measurement variables on each latent construct are presented in Table 2. The table provides the unstandardized and standardized coefficients as well as the p-values of each coefficient. To identify each latent construct, we set the scale of the metric of one of the measurement variables (indicated by an unstandardized coefficient of 1.00). ACEs and use of violence as latent variables are represented by multiple indicators. The factor loadings for each latent construct is considerable and significant.

The structural effects, presented in Fig. $1^{6}$, support our first hypothesis. ACEs were positively related to perpetrating physical violence $(\beta=.25, \mathrm{p} \leq .001)$, indicating that ACEs have a significant effect on using physical violence against an intimate partner before incarceration among women prisoners. Several demographics were also significantly related to ACEs and reported use of violence. Being African American had a negative effect on experiencing ACEs $(\beta=-.18, p \leq .01)$, indicating that African American women reported fewer ACEs than White women in the sample. Additionally, ACEs had a negative effect on some technical or college education $(\beta=-.16, p \leq .05)$, suggesting that women prisoners who experienced more ACEs were less likely to have attained either technical or college education than women who experienced fewer ACEs. Cohabit had a positive effect on using violence against an intimate partner $(\beta=.29, \mathrm{p} \leq .001)$, suggesting that women prisoners who cohabitated were more likely to report using physical violence against their intimate partner than women who were married prior to incarceration. Furthermore, not being married/ widowed had a positive effect on reported use of physical violence $(\beta=.13, \mathrm{p} \leq .05)$, indicating that women who were not married/ widowed were significantly more likely to report having perpetrated physical violence against their intimate partner than women who were married. The $\mathrm{R}^{2}$ value for use of violence in the Baseline Model was .16 . The baseline predicting the perpetration of physical violence fits the data relatively well $\left(\chi^{2}=188.17\right.$, $(126 \mathrm{df}), \mathrm{p} \leq .01$; RMSEA .038; CFI $\left.=.95\right)$.

\subsection{Theoretical model}

The baseline model suggests that ACEs are associated significantly with reported perpetration of physical violence against an intimate partner. Next, we examined whether the relationship between ACEs is fully or partially mediated by PTSD. The theoretical model estimates the effects of ACEs, controlling for the effects of social demographics, on reported perpetration of physical violence against an intimate partner, mediated by PTSD symptomology. Table 3 presents the unstandardized and standardized factor loadings, along with the p-values, of the observed variables on each construct. The theoretical model has one more variable, PTSD symptoms, measured as a latent construct represented by multiple indicators (i.e., re-experiencing, avoidance and numbing, arousal symptoms). The factor loadings for each latent construct are appreciable and significant. All loadings exceed or approach .5. The loadings are all statistically significant $(\mathrm{p} \leq .001)$.

The structural effects in the theoretical model are represented in Fig. 2. ACEs have a positive effect on PTSD ( $\beta=.60$, $\mathrm{p} \leq .001)$, as predicted. This effect is independent of age, race, education, and marital status. Moreover, PTSD has a positive and significant effect on reported perpetration of physical violence $(\beta=.30, p \leq .001)$, indicating that PTSD has a significant effect on using physical violence against an intimate partner, as predicted. However, in contrast to the Baseline Model, ACEs are no longer directly related to reported use of physical violence once PTSD is added to the equation. This suggests that the effect of ACEs on the perpetration of physical violence is fully mediated by PTSD, as predicted. Moreover, several demographics were also significantly related to ACEs, PTSD, and perpetration of physical violence. Similar to the Baseline Model, being African American had a negative effect on experiencing ACEs $(\beta=-.19, \mathrm{p} \leq .01)$, indicating that African American women prisoners were less likely to report ACEs

\footnotetext{
${ }^{5}$ We included incarceration offense type for descriptive purposes. We did explore the effects of incarceration offense type on ACEs, PTSD, and perpetration of physical violence; however, we did not include them in the final models presented here because the findings did not reveal any significant results.

${ }^{6}$ The analysis of both the baseline and theoretical model included the covariance between childhood emotional abuse and having lived with someone with a substance abuse problem, and physical neglect and emotional neglect ACEs.
} 
Table 2

Measurement Model for Baseline Model.

\begin{tabular}{|c|c|c|c|}
\hline Construct and Indicators & Unstandardized & Standardized & $\mathrm{p}$ \\
\hline \multicolumn{4}{|l|}{ ACES } \\
\hline Physical Neglect & 1.00 & .61 & .00 \\
\hline Emotional Neglect & .89 & .57 & .00 \\
\hline Emotional Abuse & .95 & .60 & .00 \\
\hline Physical Abuse & 1.09 & .58 & .00 \\
\hline Sexual Abuse & 1.21 & .63 & .00 \\
\hline Mother Battered & .95 & .54 & .00 \\
\hline Lived w/ Someone w/ Mental Illness & 1.14 & .58 & .00 \\
\hline Parental Separation or Divorce & .92 & .54 & .00 \\
\hline Incarcerated Family Member & .94 & .56 & .00 \\
\hline Lived w/ Someone w/ Substance Abuse & .94 & .57 & .00 \\
\hline \multicolumn{4}{|l|}{ Physical Violence } \\
\hline Simple Assault & 1.00 & .88 & \\
\hline Aggravated Assault & .57 & .77 & .00 \\
\hline
\end{tabular}

Note: $\chi^{2}=188.17$ (126 df), $\mathrm{p} \leq .01$, RMSEA .038; CFI $=.95$.

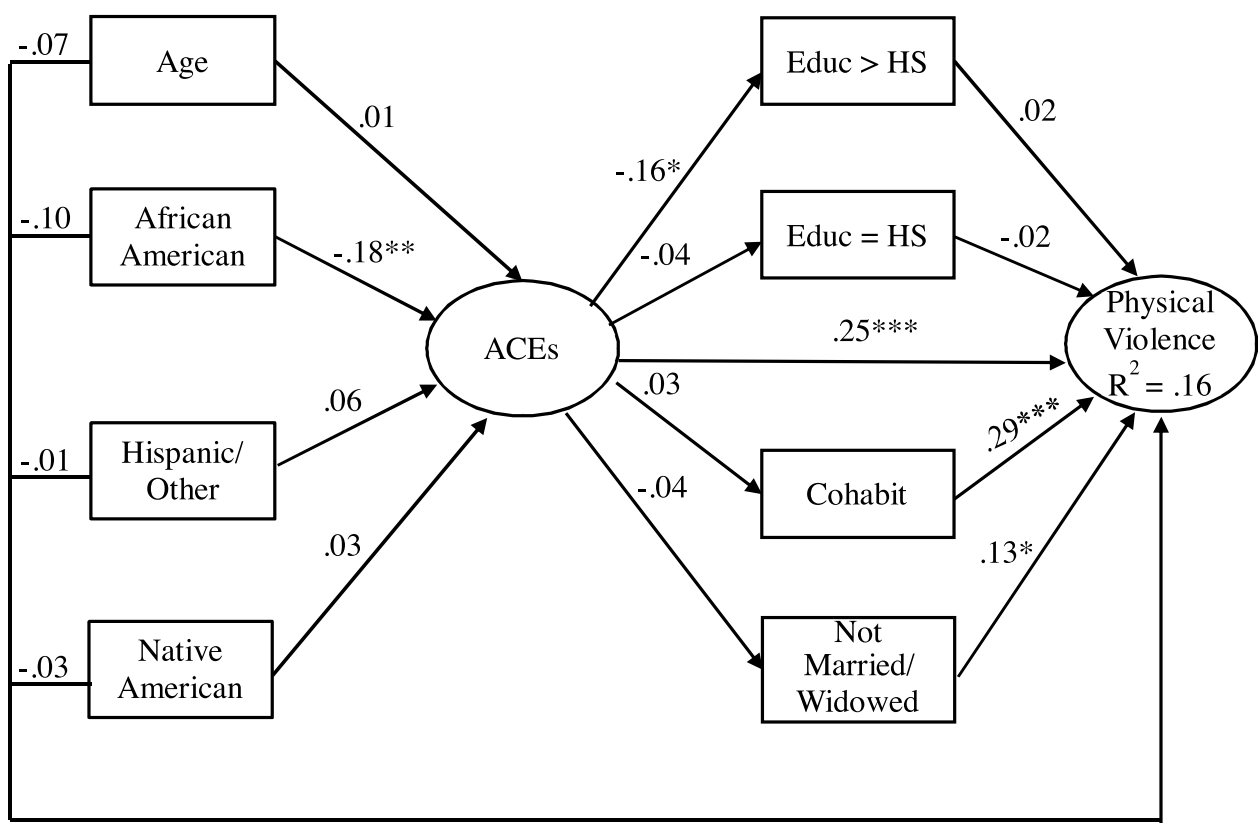

Fig. 1. Baseline Model Illustrating the Relationship Between ACEs and the Perpetration of Physical Violence Against an Intimate Partner. Note: $\chi^{2}=188.17(126 \mathrm{df}),{ }^{*} \mathrm{p} \leq .05,{ }^{* *} \mathrm{p} \leq .01{ }^{* * *} \mathrm{p} \leq .001$; RMSEA .038; CFI $=.95$

than White women in the sample. Being Native American had a negative effect on PTSD ( $\beta=-.09, \mathrm{p} \leq .05)$, suggesting that Native American women prisoners were less likely to report PTSD symptoms compared to White women. Similar to the Baseline Model, ACEs were negatively associated with some technical or college education $(\beta=-.16, p \leq .01)$ among women prisoners. Cohabitating $(\beta=.29, \mathrm{p} \leq .001)$ and not married/widowed $(\beta=.16, \mathrm{p} \leq .05)$ were both positively related to reporting use of violence, suggesting that non-married women prisoners are more likely to report having perpetrated physical violence against an intimate partner compared to married women. The $\mathrm{R}^{2}$ value for PTSD was .38 and the $\mathrm{R}^{2}$ for perpetration of physical violence improved to .25 from .16 at the Baseline Model, which suggests that PTSD may be an important mechanism by which ACEs are associated with women's perpetration of intimate partner violence. The Theoretical Model predicting the use of violence against an intimate partner fits the data relatively well $\left(\chi^{2}=232.23,(172 \mathrm{df}), \mathrm{p} \leq .01\right.$; RMSEA $\left..022 ; \mathrm{CFI}=.98\right)$.

\section{Discussion and conclusion}

A growing body of life course and ACE literature demonstrates that ACE exposure can be detrimental for adolescent and adult development, and is linked to both mental health problems in adulthood, as well as use of physical violence in intimate relationships. However, the majority of this literature focuses on non-incarcerated populations, which as a group have much lower exposure to 
Table 3

Measurement Model for Theoretical Model.

\begin{tabular}{|c|c|c|c|}
\hline Construct and Indicators & Unstandardized & Standardized & $\mathrm{p}$ \\
\hline \multicolumn{4}{|l|}{ ACES } \\
\hline$\overline{\text { Physical neglect }}$ & 1.00 & .58 & .00 \\
\hline Emotional neglect & .89 & .61 & .00 \\
\hline Emotional abuse & .97 & .56 & .00 \\
\hline Sexual abuse & 1.16 & .61 & .00 \\
\hline Physical abuse & 1.03 & .55 & .00 \\
\hline Mother battered & .94 & .54 & .00 \\
\hline Lived $\mathrm{w} /$ someone $\mathrm{w} /$ mental illness & .94 & .58 & .00 \\
\hline Parental separation or divorce & .91 & .53 & .00 \\
\hline Incarcerated family member & .83 & .57 & .00 \\
\hline Lived $\mathrm{w} /$ someone $\mathrm{w} /$ substance abuse & .93 & .56 & .00 \\
\hline \multicolumn{4}{|l|}{ PTSD } \\
\hline Re-experiencing & 1.00 & .80 & .00 \\
\hline Avoidance and numbing & 1.62 & .88 & .00 \\
\hline Arousal symptoms & 1.87 & .88 & .00 \\
\hline \multicolumn{4}{|l|}{ Physical Violence } \\
\hline Simple Assault & 1.00 & .86 & .00 \\
\hline Aggravated Assault & .56 & .80 & .00 \\
\hline
\end{tabular}

Note: $\chi^{2}=232.23(172 \mathrm{df}), \mathrm{p} \leq .01$; RMSEA .022 ; CFI $=.98$.

ACEs than those in the criminal justice system. Our analysis adds to this important body of literature by examining the relationships between ACEs, PTSD symptomology, and the perpetration of physical violence against an adult intimate partner in a sample of Oklahoma women prisoners. Specifically, this study explored: (a) whether women who reported ACEs were more likely to report both PTSD symptoms and perpetrating physical violence against and adult intimate partner, and (b) whether PTSD mediated the relationship between ACEs and physical violence perpetration. We found support for both of our hypotheses. ACEs were positively related to perpetrating physical violence against an adult intimate partner for women prisoners, which has also been supported by studies on non-incarcerated samples (Mckinney et al., 2009; Milaniak \& Widom, 2015; Miller et al., 2011; Widom et al., 2014). Our results suggest that adverse childhood events may place women on a life course trajectory where they may become more vulnerable to perpetrating adult aggression and violence, particularly in their intimate relationships. Adverse childhood events, such as physical abuse or neglect, are known to lead to dysfunctional attachment styles, social incompetence, and greater relational challenges (e.g., less positive perception about current romantic partner, more likely to have cohabitated with romantic partners, higher rates of divorce, or lesser likelihood to remain sexually faithful) (Colman \& Widom, 2004). Moreover, exposure to ACEs may shape conflict management strategies in romantic relationships (Tschann et al., 2008). From a social learning theory perspective, these experiences of violence during childhood, such as being a victim of abuse or witnessing parental violence, may convey the message that using violence is a reasonable approach to minimize differences in a conflict-ridded relationship (Eriksson \& Mazerolle, 2015). This may be especially true among the women prisoners in our sample who reported a significant number of childhood maltreatment (abuse and neglect) and chaotic home environment ACEs.

Our study also showed that ACEs were significantly and positively-related to PTSD symptomology. Previous studies have welldocumented the deleterious impact of ACEs on mental health (Chapman et al., 2004; Jones, Nurius et al., 2018; Lowe et al., 2016; Merrick et al., 2017; Taillieu et al., 2016; Widom, 1999). This is particularly true for women involved in the criminal justice system who reported alarmingly high incidences of ACEs. In our sample of women prisoners, more than half of the women report childhood physical or emotional neglect, sexual abuse, parental separation or divorce, and having lived with someone with substance abuse problems. In results not shown, over half of the women reported 5 or more ACEs with $20 \%$ reporting 7 or more ACEs, which has been documented in other studies on incarcerated women (Messina \& Grella, 2006; Messina et al., 2007; Sharp, 2014). Furthermore, more than two-thirds of the women reported re-experiencing, avoidance and numbing, and arousal symptoms of PTSD.

The main purpose of this study was to explore the potential mediating effect of PTSD symptoms in the relationship between ACEs and the perpetration of physical violence against an adult intimate partner. We found that PTSD symptoms fully mediated the association between ACEs and violence perpetration in intimate partner relationships, suggesting that PTSD symptoms may be a central mechanism in pathways to using physical violence in the adult intimate relationships of criminal justice involved women. This is the most significant finding of this study and adds to both the growing body of life course and ACE literature (Elder, 1994; Felitti et al., 1998; Merrick et al., 2017; Nurius et al., 2015) as well as research on women's pathways to incarceration (Belknap \& Holsinger, 2006; Jones, Worthen, Worthen et al., 2018, 2019; Owen, 1998; Sharp, 2014). Experiences of abuse, neglect, and chaotic home environment ACEs can cause significant harm in the developmental process and have a lasting impact on adult mental health (Afifi et al., 2011; Chapman et al., 2004; Lowe et al., 2016; McLaughlin et al., 2012; Merrick et al., 2017). Indeed, when a child is abused or neglected-the consequences can be far-reaching (Taillieu et al., 2016). Women who have difficulty managing PTSD symptoms (e.g., re-experiencing, avoidance and numbing, arousal symptoms) in response to ACEs and other traumatic life events may develop the tendency to suppress these symptoms, which may make it difficult to control other emotions, such as anger (Kubiak et al., 2017; Swan 


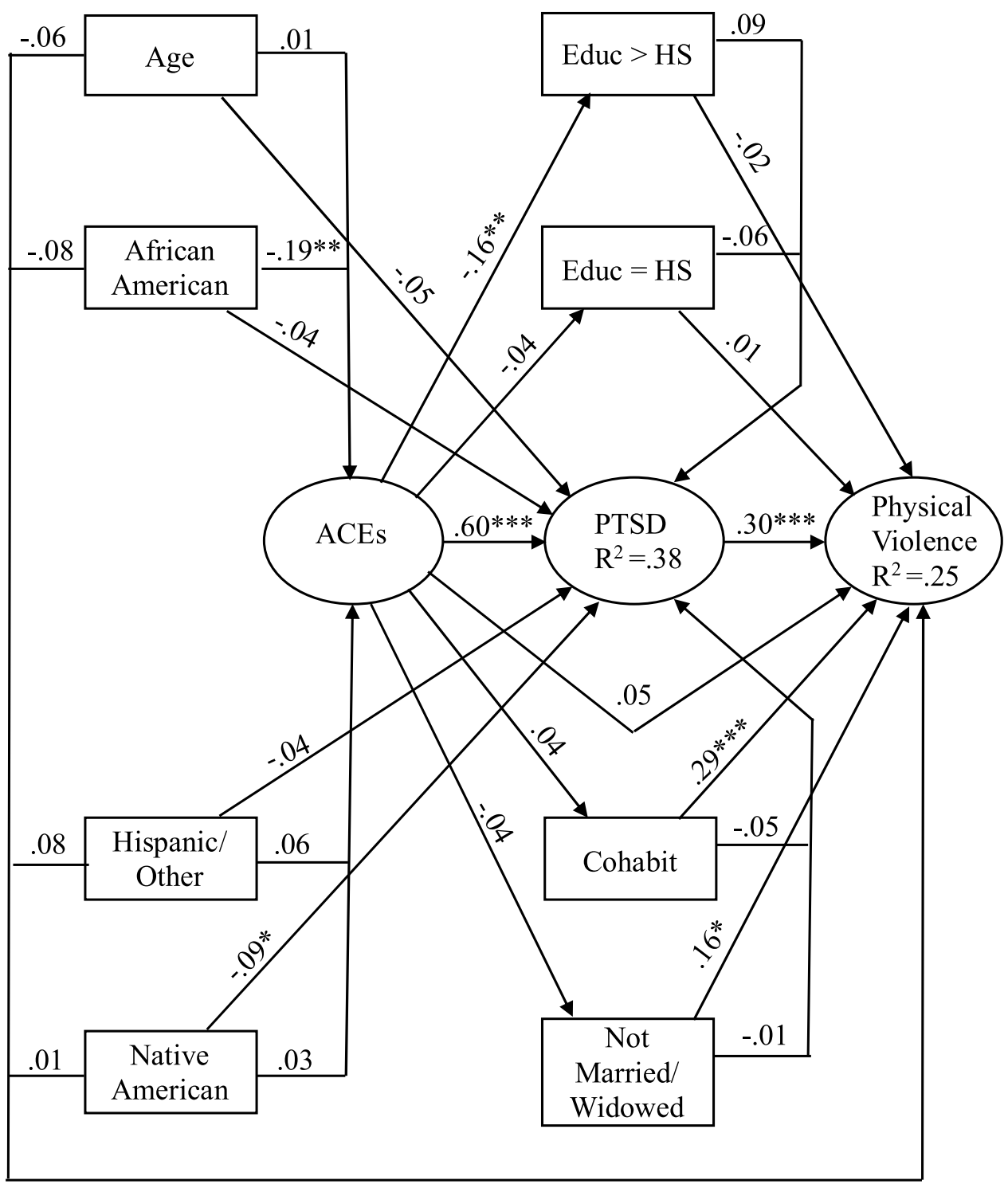

Fig. 2. Theoretical Model Illustrating the Relationship Between ACEs, PTSD, and the Perpetration of Physical Violence Against an Intimate Partner. Note: $\chi^{2}=232.23(172 \mathrm{df}),{ }^{*} \mathrm{p} \leq .05,{ }^{* *} \mathrm{p} \leq .01 * * * \mathrm{p} \leq .001 ;$ RMSEA .022 ; CFI $=.98$

et al., 2005), and can lead to aggressive behavior including perpetrating violence against an intimate partner (Brown et al., 2015; Hellmuth et al., 2013; Kendra et al., 2012; Kubiak et al., 2017; Sullivan et al., 2005). Future research should continue to explore these complex relationships in the lives of women prisoners, as such findings likely have important implications for both the criminal justice system as well as the rehabilitation of incarcerated women.

Overall, this study's findings are consistent with both the life course perspective, which emphasizes the importance of early life events in terms of human development trajectories, as well as the ACE literature, which continues to document that childhood trauma, abuse, and neglect leads to harm well into the transition to adulthood. Consistent with previous work on incarcerated women (Kubiak et al., 2017; Sharp, 2014), many of the women in our study reported experiences with multiple ACEs, high levels of PTSD symptomology, and subsequent use of physical violence against their adult intimate partners before their incarceration. More specifically, the current study's findings demonstrate that PTSD symptomology is central to understanding the relationship between ACEs and use of physical violence in adult intimate relationships. This is important because previous studies have not sufficiently examined these relationships in the lives of women prisoners. In doing so, this study provides added insights into the complex relationships between early life trauma and abuse, the development of mental illnesses, and the perpetration of violence in adult intimate relationships, and further highlights the importance of continued exploration of these processes. 


\subsection{Limitations and future research}

There are several limitations with this study that warrant mention. First our measures of ACEs are slightly limited. While we utilize some of the same measures outlined by Felitti and colleagues' (1998) ACE Study, there are other adverse childhood events that may contribute to the development of PTSD symptomology and the perpetration of physical violence against an adult intimate partner, such as the death of a loved one or parent. Furthermore, we are unable to determine the frequency or duration of exposure to ACEs. Future research should continue to explore the effects of ACEs on the perpetration of physical violence in adult intimate relationships of women prisoners by considering additional forms of ACEs as well as the duration and frequency of ACEs.

Second, while our survey asked about life events in a way structured to gain life history data, our data are cross-sectional and retrospective in nature. Thus, we are unable to determine whether women's perpetration of physical violence against their intimate partner is independent of potential violence perpetrated against them by the same partner. In other words, it remains unclear whether the women prisoners in our sample initiated the violence against their intimate partner or if they were responding in self-defense to the violence initiated against them (Bair-Merritt et al., 2010; Hamberger \& Larsen, 2015), or if both were participating in what has been termed "common couple violence" (Johnson, 2008). There may be significant overlap between perpetrating and being a victim of physical violence among women prisoners (Caldwell, Swan, Allen, Sullivan, \& Snow, 2009). In addition, due to the nature of our data, we cannot definitively establish an independent causal relationship between ACEs and the perpetration of physical violence, although past work suggests that women's use of violence in intimate relationships is directly associated with their exposure to ACEs (Miller et al., 2011; Paat \& Markham, 2019; Widom et al., 2014). Longitudinal studies that measure the timing and onset of intimate partner violence (IPV) experiences would help clarify these relationships and would be important in future research.

\subsection{Policy implications}

Despite these limitations, this study has important policy implications. Based on our results and prior ACE literature, traumainformed healthcare approaches that recognize the need for ACE and trauma screening practices may help clinicians and other healthcare professionals monitor, identify, and address the psychological and behavioral repercussions of ACEs early on in the life course (Dube, 2018; Finkelhor, 2018). Furthermore, criminologists and policy makers should consider the complex relationships between ACEs, PTSD symptomology, and the perpetration of physical violence in intimate relationships in understanding women's overall use of violence and pathways toward prison. Given the prevalence of ACEs and PTSD symptoms, as well as the significant number of women in our sample who reported using some form of violence against their intimate partner before coming to prison, it is imperative that prisons implement programming to help women understand the strong linkages between their childhood adversity, mental health, and offending behaviors. Moreover, because PTSD symptoms are a central mechanism in understanding the relationship between ACEs and the perpetration of physical violence later on in the life course, it is critical that women prisoners receive help in resolving emotional and psychological issues that resulted from these childhood adversities. Helping these women resolve emotional and psychological distress, coupled with teaching them how to develop healthy alternative coping strategies, could help empower these women whose lives are often riddled with trauma and abuse. This in turn could also further help prepare these women for their re-integration back into society.

\section{References}

Afifi, T. O., Mather, A., Boman, J., Fleisher, W., Enns, M. W., MacMillan, H., ... Sareen, J. (2011). Childhood adversity and personality disorders: Results from a nationally representative population-based study. Journal of Psychiatric Research, 45(6), 814-822.

American Psychiatric Association (2013). Diagnostic and statistical manual of mental disorders (5 ${ }^{\text {th }}$ ed.). Arlington, VA: American Psychiatric Publishing.

Bair-Merritt, M. H., Crowne, S. S., Thompson, D. A., Sibinga, E., Trent, M., \& Campbell, J. (2010). Why do women use intimate partner violence? A systematic review of women's motivations. Trauma, Violence \& Abuse, 11, 178-189.

Belknap, J., \& Holsinger, K. (2006). The gendered nature of risk factors for delinquency. Feminist Criminology, 1, 48-71.

Bentler, P. M. (1990). Comparative fit indexes in structural models. Psychological Bulletin, 107, 238-246.

Bloom, B., Owen, B., \& Covington, S. (2003). Gender-responsive strategies: Research, practice, and guiding principles for women offenders. Washington, DC: U.S. National Institute of Corrections, U.S. Department of Justice.

Bowles, M. A., DeHart, D. D., \& Webb, J. R. (2012). Family influences on female offenders' substance use: The role of adverse childhood events among incarcerated women. Journal of Family Violence, 27, 681-686.

Bronson, J., \& Berzofsky, M. (2017). Indicators of mental health problems reported by prisoners and jail inmates, 2011-2012 (NCJ250612)Retrieved from:. Department of Justice/Bureau of Justice Statisticshttps://www.bjs.gov/content/pub/pdf/imhprpji1112.pdf.

Brown, M. J., Perera, R. A., Masho, S. W., Mezuk, B., \& Cohen, S. A. (2015). Adverse childhood experiences and intimate partner aggression in the US: Sex differences and similarities in psychosocial mediation. Social Science \& Medicine, 131, 48-57.

Browne, M. W., \& Cudeck, R. (1992). Alternative ways of assessing model fit. Sociological Methods \& Research, 21, $230-258$.

Caldwell, J. E., Swan, S. C., Allen, C. T., Sullivan, T. P., \& Snow, D. L. (2009). Why I hit him: Women's reasons for intimate partner violence. Journal of Aggression, Maltreatment \& Trauma, 18(7), 672-697.

McClellan, D. S., Farabee, D., \& Crouch, B. M. (1997). Early victimization, drug use, and criminality: A comparison of male and female prisoners. Criminal Justice and Behavior, 24, 455-476.

Chapman, D. P., Whitfield, C. L., Felitti, V. J., Dube, S. R., Edwards, V. J., \& Anda, R. F. (2004). Adverse childhood experiences and the risk of depressive disorders in adulthood. Journal of Affective Disorders, 82, 217-225.

Chapman, D. P., Dube, S. R., \& Anda, R. F. (2007). Adverse childhood events and risk factors for negative mental health outcomes. Psychiatric Annals, 37, 359-364. Colman, R. A., \& Widom, C. P. (2004). Childhood abuse and neglect and adult intimate relationships: A prospective study. Child Abuse \& Neglect, $28,1133-1151$.

Covey, H. C., Menard, S., \& Franzese, R. J. (2013). Effects of adolescent physical abuse, exposure to neighborhood violence, and witnessing parental violence on adult socioeconomic status. Child Maltreatment, 18, 85-97.

Currie, J., \& Widom, C. S. (2010). Long-term consequences of child abuse and neglect on adult economic well-being. Child Maltreatment, 15, 111-120.

Dannefer, D. (2011). Age, the life course, and the sociological imagination: Prospects for theory. In R. Binstock, \& L. George (Eds.). Handbook of aging and the social 
sciences (pp. 3-16). .

DeHart, D., Lynch, S., Belknap, J., Dass-Brailsford, P., \& Green, B. (2014). Life history models of female offending: The roles of serious mental illness and trauma in women's pathways to jail. Psychology of Women Quarterly, 38, 138-151.

Dong, M., Anda, R. F., Felitti, V. J., Dube, S. R., Williamson, D. F., Thompson, T. J., ... Giles, W. H. (2004). The interrelatedness of multiple forms of childhood abuse, neglect, and household dysfunction. Child Abuse \& Neglect, 28, 771-784.

Dube, S. R., Anda, R. F., Felitti, V. J., Chapman, D. P., Williamson, D. F., \& Giles, W. H. (2001). Childhood abuse, household dysfunction, and the risk of attempted suicide throughout the life span: Findings from the adverse childhood experiences study. JAMA, 286, 3089-3096.

Dube, S. R., Felitti, V. J., Dong, M., Chapman, D. P., Giles, W. H., \& Anda, R. F. (2003). Childhood abuse, neglect, and household dysfunction and the risk of illicit drug use: The adverse childhood experiences study. Pediatrics, 111, 564-572.

Dube, S. R. (2018). Continuing conversations about adverse childhood experiences (ACEs) screening: A public health perspective. Child Abuse \& Neglect, 85, 180-184.

Dye, H. (2018). The impact and long-term effects of childhood trauma. Journal of Human Behavior in the Social Environment, $28,381-392$.

Elder, G. H. (1994). Time, human agency, and social change: Perspectives on the life course. Social Psychology Quarterly, 57, 4-15.

Elder, G. H., Jr, Johnson, M. K., \& Crosnoe, R. (2003). The emergence and development of life course theory. In J. Mortimer, \& M. J. Shanahan (Eds.). Handbook of the life course (pp. 3-19). .

Elman, C., \& O'Rand, A. M. (2004). The race is to the swift: Socioeconomic origins, adult education, and wage attainment. American Journal of Sociology, 110(1), $123-160$.

Eriksson, L., \& Mazerolle, P. (2015). A cycle of violence? Examining family-of-origin, attitudes, and intimate partner violence perpetration. Journal of Interpersonal Violence, 30, 945-964.

Felitti, V. J., Anda, R. F., Nordenberg, D., Williamson, D. F., Spitz, A. M., Edwards, V., ... Marks, J. S. (1998). Relationship of childhood abuse and household dysfunction to many of the leading causes of death in adults: The adverse childhood experiences (ACE) study. American Journal of Preventative Medicine, 14, $245-258$.

Finkelhor, D. (2018). Screening for adverse childhood experiences (ACEs): Cautions and suggestions. Child Abuse \& Neglect, 85, $174-179$.

Golding, J. M. (1990). Intimate partner violence as a risk factor for mental disorders: A meta-analysis. Journal of Family Violence, $14,99-132$.

Greenfield, E. A., \& Marks, N. F. (2010). Identifying experiences of physical and psychological violence in childhood that jeopardize mental health in adulthood. Child Abuse \& Neglect, 34, 161-171.

Grella, C. E., Stein, J. A., \& Greenwell, L. (2005). Associations among childhood trauma, adolescent problem behaviors, and adverse adult outcomes in substanceabusing women offenders. Psychology of Addictive Behaviors, 19, 43-53.

Grella, C. E., Lovinger, K., \& Warda, U. S. (2013). Relationships among trauma exposure, familial characteristics, and PTSD: A case-control study of women in prison and in the general population. Women \& Criminal Justice, 23, 63-79.

Hamberger, L. K., \& Larsen, S. E. (2015). Men's and women's experience of intimate partner violence: A review of ten years of comparative studies in clinical samples; part I. Journal of Family Violence, 30, 699-717.

Hellmuth, J. C., Jaquier, V., Young-Wolff, K., \& Sullivan, T. P. (2013). Posttraumatic stress disorder symptom clusters, alcohol misuse, and women's use of intimate partner violence. Journal of Traumatic Stress, 26, 451-458.

Johnson, M. P. (2008). A typology of domestic violence. Lebanon, NH: Northeastern University Press.

Jones, M. S., Worthen, M. G. F., Sharp, S. F., \& McLeod, D. A. (2018). Bruised inside out: The adverse and abusive life histories of incarcerated women as pathways to PTSD and illicit drug use. Justice Quarterly, 35, 1004-1029.

Jones, M. S., Worthen, M. G. F., Sharp, S. F., \& McLeod, D. A. (2018). Life as she knows it: The effects of adverse childhood experiences on intimate partner violence among women prisoners. Child Abuse \& Neglect, 85, 68-79.

Jones, M. S., Peck, B. M., Sharp, S. F., \& McLeod, D. A. (2019). Childhood adversity and intimate partner violence in adulthood: The mediating influence of PTSD in a sample of women prisoners. Journal of Interpersonal Violence. https://doi.org/10.1177/0886260519844277.

Jones, T. M., Nurius, P., Song, C., \& Fleming, C. M. (2018). Modeling life course pathways from adverse childhood experiences to adult mental health. Child Abuse \& Neglect, 80, 32-40.

Kendra, R., Bell, K. M., \& Guimond, J. M. (2012). The impact of child abuse history, PTSD symptoms, and anger arousal on dating violence perpetration among college women. Journal of Family Violence, 27, 165-175.

Kubiak, S., Fedock, G., \& Kim, W. J. (2017). Examining perpetration of physical violence by women: The influence of childhood adversity, victimization, mental illness, and substance abuse, and anger. Violence and Victims, 32, 22-45.

Lowe, S. R., Quinn, J. W., Richards, C. A., Pothen, J., Rundle, A., Galea, S., ... Bradley, B. (2016). Childhood trauma and neighborhood-level crime interact in predicting adult posttraumatic stress and major depression symptoms. Child Abuse \& Neglect, 51, $212-222$.

Mckinney, C. M., Caetano, R., Ramisetty-Mikler, S., \& Nelson, S. (2009). Childhood family violence and perpetration and victimization of intimate partner violence: Findings from a national population-based study of couples. Annals of Epidemiology, 19, 25-32.

McLaughlin, K. A., Green, J. G., Gruber, M. J., Sampson, N. A., Zaslavsky, A. M., \& Kessler, R. C. (2012). Childhood adversities and first onset of psychiatric disorders in a national sample of US adolescents. Archives of General Psychiatry, 69(11), 1151-1160.

Merrick, M. T., Ports, K. A., Ford, D. C., Afifi, T., Gershoff, E. T., \& Grogan-Kaylor, A. (2017). Unpacking the impact of adverse childhood experiences on adult mental health. Child Abuse \& Neglect, 69, 10-19.

Merrick, M. T., Ford, D. C., Ports, K. A., \& Guinn, A. S. (2018). Prevalence of adverse childhood experiences from the 2011-2014 behavioral risk factor surveillance system in 23 States. JAMA Pediatrics, 172(11), 1038-1044.

Mersky, J. P., Topitzes, J., \& Reynolds, A. J. (2013). Impacts of adverse childhood experiences on health, mental health, and substance use in early adulthood: A cohort study of an urban, minority sample in the US. Child Abuse \& Neglect, 37(11), 917-925.

Messina, N., \& Grella, C. (2006). Childhood trauma and women's health outcomes in a California prison population. American Journal of Public Health, 96, 1842-1848. Messina, N., Grella, C., Burdon, W., \& Prendergast, M. (2007). Childhood adverse events and current traumatic distress. Criminal Justice and Behavior, 34, 1385-1401.

Milaniak, I., \& Widom, C. S. (2015). Does child abuse and neglect increase risk for perpetration of violence inside and outside the home? Psychology of Violence, 5, $246-255$.

Miller, E., Bresalu, J., Chjung, W. J., Green, J. G., McLaughlin, K. A., \& Kessler, R. C. (2011). Adverse childhood experiences and risk of physical violence in adolescent dating relationships. Journal of Epidemiology and Community Health, 65, 1006-1013.

Miller-Graff, L. E., Scrafford, K., \& Rice, C. (2016). Conditional and indirect effects of age of first exposure on PTSD symptoms. Child Abuse \& Neglect, 51, 303-312.

Montez, J. K., \& Hayward, M. D. (2014). Cumulative childhood adversity, educational attainment, and active life expectancy among US adults. Demography, 51(2), $413-435$.

Nurius, P. S., Green, S., Grenne-Logan, P., \& Borja, S. (2015). Life course pathways of adverse childhood experiences toward adult psychological well-being: A stress process analysis. Child Abuse \& Neglect, 45, 143-153.

ODOC (2015). 2014 annual reportRetrieved from. Oklahoma Department of Correctionshtts://www.ok.gov/doc/documents/annual\%20report\%202014.final\%20. copy.website.pdf.

Owen, B. (1998). In the mix: Struggle and survival in a women's prison. New York, NY: State University Press.

Paat, Y., \& Markham, C. (2019). The roles of family factors and relationship dynamics on dating violence victimization and perpetration among college men and women in emerging adulthood. Journal of Interpersonal Violence, 34, 81-114.

Ports, K. A., Ford, D. C., \& Merrick, M. T. (2016). Adverse childhood experiences and sexual victimization in adulthood. Child Abuse \& Neglect, 51, 313-322.

Roberts, A. L., McLaughlin, K. A., Conron, K. J., \& Koenen, K. C. (2011). Adulthood stressors, history of childhood adversity, and risk of perpetration of intimate partner violence. American Journal of Preventative Medicine, 40, 128-138.

Roxburgh, S., \& MacArthur, K. R. (2014). Childhood adversity and adult depression among the incarcerated: Differential exposure and vulnerability by race/ethnicity and gender. Child Abuse \& Neglect, 38, 1409-1420. 
Schafer, M. H., Ferraro, K. F., \& Mustillo, S. A. (2011). Children of misfortune: Early adversity and cumulative inequality in perceived life trajectories. American Journal of Sociology, 116(4), 1053-1091.

Schafer, M. H., Wilkinson, L. R., \& Ferraro, K. F. (2013). Childhood (mis) fortune, educational attainment, and adult health: Contingent benefits of a college degree? Social Forces, 91(3), 1007-1034.

Settersten, R. A., Jr (2015). Relationships in time and the life course: The significance of linked lives. Research in Human Development, 12(3-4), 217-223.

Sharp, S. F. (2014). Mean Lives, mean laws: Oklahoma's women prisoners. New York, NY: Oxford University Press.

Sharp, S. F., Peck, B. M., \& Harstfield, J. (2012). Childhood adversity and substance use of women prisoners: A general strain theory approach. Journal of Criminal Justice, 40, 202-211.

Straus, M. A., Hamby, S. L., Boney-McCoy, S., \& Sugarman, D. B. (1996). The revised conflict tactics scales (CTS2): Development and preliminary psychometric data. Journal of Family Issues, 17, 283-316.

Sullivan, T. P., Meese, K. J., Swan, S. C., Mazure, C. M., \& Snow, D. L. (2005). Precursors and correlates of women's violence: Child abuse traumatization, victimization of women, avoidance coping, and psychological symptoms. Psychology of Women Quarterly, 29, 290-301.

Swan, S. C., Gambone, L. L., Fields, A. M., Sullivan, T. P., \& Snow, D. L. (2005). Women who use violence in intimate relationships: The role of anger, victimization, and symptoms of posttraumatic stress and depression. Violence and Victims, 20, 267-285.

Taillieu, T. L., Brownridge, D. A., Sareen, J., \& Afifi, T. O. (2016). Childhood emotional maltreatment and mental disorders: Results from a nationally representative adult sample from the United States. Child Abuse \& Neglect, 59, 1-12.

Temple, J. R., Shorey, R. C., Tortolero, S. R., Wolfe, D. A., \& Stuart, G. L. (2013). Importance of gender and attitudes about violence in the relationship between exposure to interparental violence and the perpetration of teen dating violence. Child Abuse \& Neglect, 37, 343-352.

Tschann, J. M., Pasch, L. A., Flories, E., Marin, B. V., Baisch, E. M., \& Wibbelsman, C. J. (2008). Nonviolent aspects of interparental conflict and dating violence among adolescence. Journal of Family Issues, 30, 295-319.

Umberson, D., Williams, K., Thomas, P. A., Liu, H., \& Thomeer, M. B. (2014). Race, gender, and chains of disadvantage: Childhood adversity, social relationships, and health. Journal of Health and Social Behavior, 55(1), 20-38.

Wagmiller, R. L., Jr, Lennon, M. C., Kuang, L., Alberti, P. M., \& Aber, J. L. (2006). The dynamics of economic disadvantage and children's life chances. American Sociological Review, 71(5), 847-866.

Weathers, F. W., Litz, B. T., Herman, D. S., Huska, J. A., \& Keane, T. M. (1993). The PTSD checklist (PCL): Reliabilty, validity, and diagnostic utility. Paper Presented at the $9^{\text {th }}$ Annual Conference of the ISTSS.

Whitfield, C. L., Anda, R. F., Dube, S. R., \& Felitti, V. J. (2003). Violent childhood experiences and the risk of intimate partner violence in adults: Assessment in a large health maintenance organization. Journal of Interpersonal Violence, 18, 166-185.

Widom, C. S. (1999). Posttraumatic stress disorder in abused and neglected children grown up. American Journal of Psychiatry, $156,1223-1229$.

Widom, C. S., Czaja, S., \& Dutton, M. A. (2014). Child abuse and neglect and intimate partner violence victimization and perpetration: A prospective investigation. Child Abuse \& Neglect, 38, 650-663.

Wolf, N., Vazquez, R., Frueh, B., Shi, J., Schumann, B., \& Geradi, D. (2011). Traumatic event exposure and behavioral health disorders among incarcerated females self-referred to treatment. Psychological Injury and Law, 3, 155-163. 